Published in final edited form as:

Best Pract Res Clin Rheumatol. 2017 June ; 31(3): 306-320. doi:10.1016/j.berh.2017.09.005.

\title{
Understanding the role of environmental factors in the development of Systemic Lupus Erythematosus
}

\author{
Christine G. Parks ${ }^{1}$, Aline de Souza Espindola Santos ${ }^{2}$, Medha Barbhaiya ${ }^{3}$, and Karen H. \\ Costenbader 4 \\ ${ }^{1}$ Epidemiology Branch, National Institute of Environmental Health Sciences, National Institutes of \\ Health, Department of Health and Human Services, Durham, NC \\ ${ }^{2}$ Occupational and Environmental Health Branch, Public Health Institute, Federal University of Rio \\ de Janeiro, Rio de Janeiro, Brazil \\ ${ }^{3}$ Department of Medicine, Division of Rheumatology, Hospital for Special Surgery, Weill- Cornell \\ Medical School, New York, NY \\ ${ }^{4}$ Department of Medicine, Division of Rheumatology, Immunology and Allergy, Department of \\ Medicine, Brigham and Women's Hospital, Harvard Medical School, Boston, MA
}

\section{Abstract}

Systemic lupus erythematosus (SLE) is a multisystem disease with a complex etiology. Risk is higher among women, racial and ethnic minorities, and individuals with a family history of SLE or related autoimmune diseases. It is thought that genetic factors interact with environmental exposures throughout the lifespan to influence susceptibility to developing SLE. The strongest epidemiologic evidence exists for increased risk of SLE associated with exposure to crystalline silica, current cigarette smoking, use of oral contraceptives and postmenopausal hormone replacement therapy, while there is an inverse association with alcohol use. Emerging research results suggest possible associations of SLE risk with exposure to solvents, residential and agricultural pesticides, heavy metals, and air pollution. Ultraviolet light, certain infections, and vaccinations have also been hypothesized to be related to SLE risk. Mechanisms linking environmental exposures and SLE include epigenetic modifications resulting from exposures, and increased oxidative stress, systemic inflammation and inflammatory cytokine upregulation, and hormonal effects. Research needs to include new studies of environmental risk factors for SLE generally, with a focus on lifetime exposure assessment, and studies in susceptible subgroups, such as family members or based on genetic risk profiles, or in individuals with evidence of pre-clinical autoimmunity based on detection of specific auto-antibodies. Understanding the role of

Corresponding author and reprint requests: Karen H. Costenbader, MD, MPH, Department of Medicine, Division of Rheumatology, Immunology and Allergy, Brigham and Women's Hospital, Harvard Medical School, 60 Fenwood Road, Boston, MA 02115, Phone: 617-732-5158, kcostenbader@bwh.harvard.edu.

Conflicts of Interest: None

Publisher's Disclaimer: This is a PDF file of an unedited manuscript that has been accepted for publication. As a service to our customers we are providing this early version of the manuscript. The manuscript will undergo copyediting, typesetting, and review of the resulting proof before it is published in its final citable form. Please note that during the production process errors may be discovered which could affect the content, and all legal disclaimers that apply to the journal pertain. 
environmental exposures in the development of SLE may help to identify modifiable risk factors and potential etiologic mechanisms.

\section{Keywords}

systemic lupus erythematosus; SLE; environment; risk factor; exposure; pathogenesis

\section{Introduction}

Systemic lupus erythematosus (SLE) is a complex multisystem, autoimmune disease with an incidence of approximately 5-20 per 100,000 in the U.S. population [1,2]. Female predominance of SLE (9:1 female to male), and higher SLE incidence in African Americans and native Americans in particular, point towards an important role of both intrinsic and extrinsic non-genetic factors [3,4]. Genome-wide association studies are identifying a growing list of gene contributing to SLE pathogenesis and clinical manifestations [5,6]. Having a family history of SLE or related autoimmune diseases dramatically increases risk of SLE [7], but the low to modest penetrance of genetic risk factors and concordance in twins highlight the importance of environmental factors [8].

There is strong epidemiologic evidence concerning the association of SLE with several environmental factors, including crystalline silica exposure [9,10], and alcohol consumption (decreased risk) [11], current cigarette smoking [12], and exogenous estrogens (oral contraceptives and postmenopausal hormones) $[13,14]$. Evidence also points to potential associations between other exogenous factors as reviewed below (e.g., UV radiation, solvents, pesticides; Figure 1). Associations of SLE with intrinsic factors, including birthweight, reproductive history (e.g., parity, age at menarche and menopause), endometriosis, and latent infections such as EBV, may reflect an indirect role of environmental exposures [15-17] Considerable knowledge gaps remain regarding potential mechanisms by which these environmental factors may be involved in the pathogenesis of SLE. Epigenetic regulation, whereby environmental stimuli lead to biochemical epigenetic modifications, may be a potential link (18]. Differential DNA methylation patterns have been reported in twins discordant for SLE [19]. Metabolic mechanisms that modify gene expression and precipitate SLE have also been proposed [20]. Oxidative stress has been shown to inhibit ERK pathway signaling in T cells leading to DNA demethylation, upregulation of immune genes and auto-reactivity, and could contribute to SLE onset among genetically predisposed individuals [21,22].

In this review, we summarize current knowledge about environmental factors linked to SLE risk based on epidemiologic research, with a focus on modifiable extrinsic exposures.

Potential biologic mechanisms have been recently reviewed in other contexts [23], and so we highlight specific instances when evidence is particularly strong or novel. To provide a critical perspective on the literature, we start with a framework for understanding the current state of knowledge and end with needs for new epidemiological and translational research studies of the role of the environment in SLE. 


\section{Considering the Role of Environment Factors in SLE Pathogenesis}

There is no doubt that experimental and mechanistic studies in SLE animal models and clinical studies help to elucidate potential causal exposures and etiologic pathways. Observational research also has been critical for identifying and confirming the role of environmental exposures in the development of SLE. Potential associations are often first revealed in descriptive observational studies, and confirmed across multiple populations (e.g., research on crystalline silica described below), before being substantiated in experimental studies. Understanding the strength and limitations of epidemiologic study design in SLE research is necessary to accurately interpret findings and identify opportunities for future research.

\section{Epidemiologic Study Design}

Evaluating the weight of the evidence concerning environmental exposures and SLE risk, and identifying directions for future research, depend on a balanced understanding of the strengths and limitations of epidemiologic research. Because SLE is a rare disease, the traditional retrospective case-control design is most efficient, but has a greater potential for recall bias and misclassification error. On the other hand, population-based and occupational cohort studies are typically limited by the low incidence rates and challenges in ascertaining SLE based upon self-report, which is sensitive but non-specific [24]. Methods to validate or confirm cases may introduce selection bias if specific medication use (e.g., disease modifying anti-rheumatic drugs) or if consent to medical records review is related to exposures or varies by major demographic subgroups (e.g., by age, sex or other social factors). Cases defined based on medication use may represent a clinical diagnosis, but may not meet validated classification criteria for SLE. In practice, challenges in case ascertainment also reflect challenges in disease diagnosis, including potential for incomplete clinical features and overlap with other systemic autoimmune diseases.

While the topic of exposure assessment is beyond the scope of the current review, it is important to emphasize challenges in assessing environmental exposures [25]. The example of crystalline silica illustrates several issues in exposure assessment, including a lack of biomarkers to measure past exposures, which are typically identified by self-report in questionnaires, and low to moderate exposure levels in the general population. Occupational cohorts often have higher levels and well-quantified exposures, but SLE is a rare outcome and covariate data may be unavailable. Although an association between silica exposure and SLE is highly probable, key questions remain concerning dose and timing and biologic mechanisms involved in triggering or promoting SLE; answers may rely on experimental studies in susceptible models.

\section{Susceptible Subgroups and Preclinical SLE}

The goals of research on environmental exposures and SLE risk include the identification of causal risk factors that can be modified to reduce the burden of disease, as well as having an improved understanding of disease pathogenesis. An underlying conceptual model is necessary to address the timing and mechanisms by which environmental factors interact with genetic factors and inherent susceptibility, initiating and promoting the development of 
disease. Susceptibility to SLE may be defined based on family history of SLE or related diseases, patterns of genetic variation, or preclinical phenotypes. Studies of family members are essentially "at-risk cohorts", enriched for genetic (and early environmental) risk factors. SLE is a rare outcome in the general population, so individuals screening positive for autoantibodies, e.g., antinuclear antibodies (ANA), may provide another source of potential "risk-enriched" samples. However, while ANA can appear years prior to SLE onset [26], they are relatively common in the general population [27]. Most studies have not examined more specific and rare SLE-associated autoantibodies, and the natural history of ANA in the general population is not well understood. Nevertheless, the relationship of exposures with markers such as ANA may indicate an initial break in self-tolerance relevant to development of autoimmune disease. The most efficient study design may be one that combines approaches to identify or describe susceptible subgroups, increasing statistical power to detect associations and interactions between risk factors.

Lastly, developmental risk factors for SLE should also be considered in the realms of exposure assessment and disease susceptibility. Maternal, prenatal and early life exposures can modify immune development and may set the stage for development of chronic autoimmune diseases such as SLE later in life. Eventually, informative epigenetic biomarkers may provide additional means to identify at-risk-individuals. While there is growing evidence of epigenetic differences in SLE patients, relatively little is known about the timing of these changes relative to SLE onset nor about how environmental factors lead to epigenetic modifications that may be involved in SLE pathogenesis. For example, increased birthweight has been inconsistently associated with SLE risk [15, 28,29], and may reflect a role of in utero nutritional intake on SLE risk mediated by epigenetic changes in immune regulation and responses to exposures in later life.

\section{Occupational Exposures and Environmental Pollutants}

\section{Silica and Silicates}

Exposure to respirable silica dust (i.e., the crystalline form from quartz) is an established risk factor for SLE and other systemic autoimmune diseases (e.g., scleroderma and rheumatoid arthritis) [30]. The association of silica exposure and increased SLE risk has been observed in occupational and residential, rural and urban settings [10,31,32], and studies show dose-response associations with increasing intensity or duration [9,33]. Large population-based studies have confirmed these findings in recent years [34,35], and occupational cohorts continue to identify potential silica-related SLE cases [36]. Critical questions remain however, including the required dose, timing and susceptibility factors, and the potential role of other silicates.

Experimental studies suggest crystalline silica acts as an immune adjuvant inducing apoptosis and release of intracellular antigens, increasing pro-inflammatory cytokines, oxidative stress and $\mathrm{T}$ cell responses and decreasing the number of regulatory $\mathrm{T}$ cells [37]. Silica exposure exacerbates lupus in murine models, increasing levels of serum autoantibodies, immune complexes, glomerulonephritis and proteinuria [38]. Notably, repeated short-term, respiratory exposures appear to be able to induce SLE-like disease, including systemic autoimmunity and glomerulonephritis [39]. This latter finding may have 
important implications for disease prevention, if short, but intense exposures are etiologically relevant.

Asbestos, a long-chain silicate, has been shown to be associated with ANA development and proteinuria, as well as with increased rheumatoid arthritis risk [40]. Researchers are studying other silicates, including asbestos, in relation to SLE risk [41], for example identifying associations of asbestos with antinuclear antibodies in an exposed community. Given the longevity of silica and silicates as natural elements in the environment, with potential for diverse human exposures, further investigation of their effects on SLE is warranted.

Other common non-occupational exposures to silicates may be of interest to future research, as well as engineered nanoparticles, which are increasingly used in processed foods, medications and personal care products. Growing evidence suggests that, depending on the context, nanoparticles can have immunostimulatory effects, for example via activation of the complement system and potential adjuvant effects [42].

\section{Other Respiratory Exposures}

Acute, high-level exposure to dusts generated in the World Trade Center Disaster has been linked to a variety of respiratory symptoms and diseases in rescue and clean-up workers [43]. Although there were few SLE cases, rates of composite systemic autoimmune diseases were elevated in workers exposed to the highest levels. Acute dust exposure from the disaster has been related to changes in markers of pulmonary inflammation, oxidative stress and epigenetic changes in experimental models [44], and different types of dust, which likely include silica, silicates and carbon nanotubes, have been associated with markers of increased systemic inflammation in a volunteer community cohort of symptomatic individuals, years after exposure $[45,46]$.

Particulate air pollution has also been hypothesized to be associated with development of systemic autoimmune rheumatic diseases (SARD), including systemic lupus, Sjogren's syndrome, scleroderma, polymyositis, dermatomyositis, and undifferentiated connective tissue disease, in an urban Canadian cohort [47]. The odds of SARD were elevated among those with higher exposures to air pollution particulate matter in two other Canadian provinces as well [48]. Levels of particulate matter in air pollution are typically much lower than seen for exposures due to occupational silica dust or those experienced in the World Trade Disaster, and so other mechanism may be operating. The extent to which such changes increase susceptibility to other exposures needs to be further examined in studies of SLE.

Mechanistic evidence exists implicating cigarette smoking in SLE pathogenesis. Exposure to toxic components from cigarette smoke (e.g. tars, nicotine, carbon monoxide, polycyclic aromatic hydrocarbons and free radicals) can induce oxidative stress and directly damage endogenous proteins and DNA, leading to genetic mutations and gene activation, which could be involved in development of SLE [49]. Cigarette smoking stimulates the expression of CD95 on B and CD4 on T cell surfaces, potentially inducing autoimmunity [50], and also augments production of pro-inflammatory cytokines [51]. A meta-analysis of studies of smoking and SLE risk revealed that current smokers had a modestly elevated SLE risk (OR $1.5 ; 95 \%$ CI 1.09, 2.08) compared to non-smokers [12]. Past smokers did not have an 
elevated risk compared to non-smokers in that meta-analysis. In recent analyses within the Nurses' Health Study prospective cohorts, current, but not past, smoking was strongly related to the risk of anti-double stranded DNA-positive subtype of SLE (1.86; 95\% CI 1.14, 3.04]) [52]. No associations were observed between past smoking, or pack-years and overall SLE or anti-double stranded DNA negative SLE. The strong and specific association of current smoking with anti-double stranded DNA seropositive SLE suggest smoking is involved in the pathogenesis of this specific subtype of SLE.

Evidence for other respiratory exposures, such as organic dust and endotoxins, is less well developed. Endotoxins can act as immune adjuvants, but findings with respect to SLE is inconsistent $[41,53]$.

\section{Other Xenobiotic Exposures}

Environmental contaminants exist in residential settings and common household products and solvents (e.g., dry cleaning solvents, nail polish removers, paints, perfumes) as well as at hazardous waste sites. These products may affect oxidative stress and/or sex hormone homeostasis [54]. Although increased SLE risk has been associated with jobs and tasks involving solvent exposure in studies utilizing different study designs [35, 55], other studies assessing solvent exposure based on job history and high-exposure work tasks have found no overall or dose-response associations with SLE $[32,56]$. However, trichloroethylene has yet to be conclusively linked to the development of SLE [57,58].

Two studies have reported that pesticide exposure, both agricultural and residential, to be associated with increased SLE risk [56,59]. A recent study confirmed these findings in a national cohort of women, but focused on childhood exposures. More frequent residential pesticide use (e.g., at least monthly, OR $2.3,95 \%$ CI $1.3,4.1$ ) and having an early and extended childhood farm residence (OR 1.8; 95\%CI 1.1,3.0) were strongly associated with SLE [15]. These findings highlight the importance of exposure assessment across the lifecourse, and considering developmental as well as adult exposures. A key limitation of these studies is that they relied on self-reported exposures, and pesticides represent a diverse set of chemical exposures with important differences in historical use. For example, organochlorine insecticides were widely used (and are still currently used in some areas and widely persist in the environment), but direct exposures may differ dramatically from current uses of herbicides and many people are exposed to multiple different kinds of pesticides. Furthermore, the strongest associations were seen in those with a history of farm-related exposures. Agricultural exposure to pesticides may be higher than the general population, and often include childhood exposures for those raised on a farm; however, farmers may have other chemical or physical exposures to factors that influence immunity, such as silica, solvents, infections, endotoxins and UV light. Thus, research is needed to identify SLE associations with specific pesticides and other chemical or other physical exposures.

Dioxins, furans, polychlorinated biphenyls (PCBs), and other polycyclic aromatic hydrocarbons are widespread organic pollutants that are persistent in the environment and bioaccumulate in the food chain. These organohalogens mediate their biologic and toxic effects through varying mechanisms, including the well-known immunosuppressive effects of 2,3,7,8-tetrachlorodibenzo-p-dioxin (TCDD) and other dioxin-like congeners [60], 
instigated by binding to the arylhydrocarbon receptor. Increased SLE mortality was observed in long-term follow-up of a Taiwanese population exposed to high levels of PCBs and furans through consumption of contaminated rice, with SLE deaths starting 10 years after the exposure [61]. Findings suggesting roles of hair dyes and other cosmetics, including lipstick, in the development of SLE remain unconfirmed [30,62].

Data from experimental studies suggest that heavy metals may increase systemic autoimmunity [25], and that effects may be direct or indirect; for example, co-exposure to certain heavy metals may increase the risk associated with other exposures [63]. A recent case-control study suggested an association of SLE with residential proximity to a uranium processing plant [64]. Two case-control studies have shown elevated risk of SLE associated with self-reported exposure to mercury [55,56]. Mercury-exposed gold miners were demonstrated to have a higher prevalence of detectable ANA as compared to diamond and emerald miners with no occupational mercury exposures [65]. However, a recent populationbased study showed no evidence of consistent or strong associations of mercury or other heavy metals with ANA in the general population [66].

\section{Other Exposures}

Although ultraviolet light (UV) radiation exposure may exacerbate pre-existing SLE, it is still not known whether UV exposure plays a role in the pathogenesis of SLE [67]. Experimental studies suggest that UV-B radiation results in induction of reactive oxygen species, leading to DNA damage [68], production of novel forms of autoantigens and autoreactive T cells $[69,70]$, and may have immunomodulatory effects on T cells and cytokines [71], all potentially involved in SLE pathogenesis. A few case-control studies have examined UV exposure and SLE risk [55,72], but these have been limited by potential inaccuracy of exposure assessment, and influenced by recall and reverse causation bias (e.g., photosensitivity due to SLE may be present prior to diagnosis). We have reviewed this topic in detail elsewhere [73]. Large, well-controlled studies are still needed to prospectively assess the relationship of UV-B radiation with incident SLE.

Further complicating our understanding of the relationship between UV radiation and SLE pathogenesis is the controversial role of vitamin $\mathrm{D}$. While exposure to solar UV radiation may trigger SLE disease flares, UV light exposure is also the main source of vitamin D [74]. Vitamin D may be immunosuppressive once metabolized to $1 \mathrm{a}, 25(\mathrm{OH})_{2} \mathrm{D} 3[75]$, and it has been suggested that UV-B radiation could reduce SLE risk via stimulation of cutaneous vitamin D synthesis [76]. Many cross-sectional and case-control studies have reported low 25(OH) vitamin D concentrations in SLE patients compared to controls; however, low vitamin D may be the consequence of chronic disease. No protective effects of vitamin D intake from foods or supplements in adult or adolescent years were found among women in the Nurses' Health Studies [76,77]. Recent research, in a susceptible subgroup (family members of a patient with SLE), suggested those with vitamin D deficiency were more likely to transition to SLE, especially in those with a particular genotype in the vitamin D metabolism pathway [78].

Other than vitamin D, few studies have examined dietary exposures in relation to SLE. Early research suggesting an association of SLE with alfalfa sprouts [79], has not been replicated 
[80]. Antioxidant intake in diet and supplements was not related to risk of SLE among women in the Nurses' Health Studies [81]. Other dietary exposures or patterns have not been well examined in human studies, for example, the Western-type diet, which in mice was associated with anti-HMGB1 autoimmunity (antibodies related to disease activity in SLE patients) [82]. Through epigenetic pathways, dietary factors may influence the risk of SLE; for example, experimental evidence suggests SLE-prone mice fed diets rich in methyl group micronutrients were less likely to develop nephritis compared to those lacking these nutrients [83].

Alcohol contains compounds (e.g. ethanol and antioxidants) that potentially counteract systemic inflammation, decreasing cellular responses to immunogens, and suppressing synthesis of pro-inflammatory cytokines, such as tumor necrosis factor (TNF), interleukin (IL)-6, IL-8, both in vivo and in vitro in alveolar macrophages and human blood monocytes [84]. Antioxidants in wine and beer influence cytokines such as interferon-gamma in vitro and may inhibit key enzymes involved in DNA synthesis [85,86]. Moderate alcohol intake may also reduce serum levels of IgG [87]. A meta-analysis of six case-control studies and one cohort study demonstrated an inverse association of moderate alcohol intake with SLE risk (OR 0.72, 95\%CI 0.55-0.95) [11]. Long-term moderate alcohol consumption ( 25 grams or 0.5 drink/day) was associated with lower risk of incident SLE (HR 0.61, 95\%CI 0.41-0.89) in the Nurses' Health Study cohorts [88], specifically in women who drank $\geq 2$ servings of wine/week (HR 0.65 ; 95\%CI 0.45-0.96) compared to women who did not drink wine.

Vaccinations have been proposed as potential triggers for the onset of SLE given their role in stimulating an antigen-specific immune response. However, these associations have not been confirmed in epidemiologic studies [89], including a recent international case-control study involving 105 SLE patients, which demonstrated no association between vaccinations administered within 24 months of SLE [90].

Infections have been suggested as causal factors for SLE. Research, however, is difficult for a variety of reasons, and the timing of exposures may be critical. Early life infections may be related to the development of immune response tendencies that might increase susceptibility to lupus later in life. Studies of recent infections (or latent viral infections) are further complicated by lack of knowledge about whether the infection is a sign of early disease activity. For example, Epstein-Barr virus (EBV) seropositivity is higher in adults and children with SLE than age-matched controls [91], but no conclusive data have established that EBV infection influences future risk of SLE. In a large population-based Danish cohort, EBV-serologic negative individuals had an increased risk for SLE, which peaked at 1 to 4 years after testing (standardized incidence rate, 6.6; 95\% CI 3.3,13.2), but this finding may be due to surveillance bias, as EBV testing is likely to be performed during the work-up for early SLE symptoms [92]. By contrast, no associations were found with EBV serologic positivity, infectious mononucleosis, or severe infectious mononucleosis requiring hospitalization [89, 92]. A recent meta-analysis of twenty-five case control studies demonstrated a statistically significant higher seroprevalence of anti-viral capsid antigen IgG (OR $2.08,95 \%$ CI 1.15 to $3.76, \mathrm{p}=0.007$ ) and antibodies to EBV early antigen diffuse, a marker of viral replication, in patients with existing SLE patients compared to normal 
individuals (OR 4.5; 95\% CI 3.00 to 11.06, $\mathrm{p}<0.00001$ ), although the funnel plot examination suggested publication bias. [93].

On the other hand, immune stimulation due to infections (or susceptibility to infections due to underlying immune dysregulation) is a plausible risk factor for SLE. Latency in the association of infections with SLE may be used to explore potential bias; in theory, more distant infections might indicate an underlying susceptibility rather than detection bias or reverse causality. But even then, interpretation may be fraught with difficulties. Recent evidence from a large registry linkage study of the Danish Population (1945- 2000), suggests associations of history for hospitalization with infection SLE diagnosis (and other autoimmune diseases), including a two-fold increase for infections at least 5 or 10 years prior to SLE diagnosis [94]. The idea that infections are a marker for immune susceptibility to SLE is supported by findings that the association of SLE with EBV-associated antibodies was stronger in patients with a particular CTLA-4 genotype [17]. Generally, investigating infection as a causal factor for SLE is complicated by the fact that rates of infection are influence by both intrinsic factors, historical exposures to infections, and factors influencing contact with infectious agents.

Sex steroid hormones, including 17- $\beta$-estradiol, testosterone, prolactin, progesterone and dehydroepiandrosterone, have multiple influences on immune system function $[95,96]$. Epidemiologic research suggests that exogenous hormone use (including both oral contraceptives [OCPS] and hormone replacement therapy [HRT]) are associated with an increased risk of SLE [14, 97]. In a large, prospective study using the Nurses' Health Study cohorts, oral contraceptives and postmenopausal HRT were both associated with increased risk of incident SLE (RR 1.5, 95\% CI 1.1-2.1 and RR 1.9, 95\% CI 1.2-3.1, respectively) [14]. Furthermore, a strong dose-response relationship was observed between the OCP dose of ethinyl estradiol and new onset SLE in a large study using data from the U.K. General Practice Database [98]. A separate study demonstrated an inverse (protective) relationship of the progesterone-only pill with SLE [99]. These findings support the research focused on the role of environmental estrogens in SLE, including a variety of chemicals listed above with potential estrogenic effects, such as some pesticides, dioxins and PCBs.

\section{Summary}

Studies identifying modifiable environmental risk factors for SLE could lead to strategies to prevent disease, especially among those individuals at high risk. Substantial epidemiologic research exists to support the associations between silica, current cigarette smoking, oral contraceptives, and postmenopausal hormone therapy with increased risk of incident SLE. Moderate alcohol consumption has been demonstrated to reduce incident SLE risk. Other environmental factors, including air pollution, ultraviolet light, solvents, pesticides, and heavy metals, may increase SLE risk, but further studies are needed to confirm these findings. Studies identifying the role of modifiable environmental risk factors in the development of SLE will advance our understanding of disease pathogenesis and could lead to strategies to prevent disease. Research will be advanced through studies in susceptible subgroups and should consider exposures across the life course. 


\section{Acknowledgments}

Financial Support and Sponsorship: Research reported in this publication was supported by the Intramural Program of the National Institute of Environmental Health Science, National Institutes of Health, the National Institute of Arthritis and Musculoskeletal and Skin Diseases under Award numbers R01 AR057327 and K24 AR066109. Dr. Barbhaiya is supported by the Rheumatology Research Foundation Scientist Development Award.

\section{References}

1. Lim SS, Bayakly AR, Helmick CG, Gordon C, Easley KA, Drenkard C. The incidence and prevalence of systemic lupus erythematosus, 2002-2004: The Georgia Lupus Registry. Arthritis Rheumatol. 2014; 66(2):357-68. [PubMed: 24504808]

2. Somers EC, Marder W, Cagnoli P, Lewis EE, DeGuire P, Gordon C, et al. Population-based incidence and prevalence of systemic lupus erythematosus: the Michigan Lupus Epidemiology and Surveillance program. Arthritis Rheumatol. 2014; 66(2):369-78. [PubMed: 24504809]

3. Ferucci ED, Johnston JM, Gaddy JR, Sumner L, Posever JO, Choromanski TL, et al. Prevalence and incidence of systemic lupus erythematosus in a population-based registry of American Indian and Alaska Native people, 2007-2009. Arthritis Rheumatol. 2014; 66(9):2494-502. [PubMed: 24891315]

4. Mccarty DJ, Manzi S, Medsger TA, Ramsey-Goldman R, Laporte RE, Kwoh CK. Incidence of systemic lupus erythematosus race and gender differences. Arthritis \& Rheumatology. 1995; 38(9): 1260-1270.

5. Sanchez E, Nadig A, Richardson BC, Freedman BI, Kaufman KM, Kelly JA, et al. Phenotypic associations of genetic susceptibility loci in systemic lupus erythematosus. Ann Rheum Dis. 2011; 70(10):1752-1757. [PubMed: 21719445]

6. Bentham J, Morris DL, Graham DSC, Pinder CL, Tombleson P, Behrens TW, et al. Genetic association analyses implicate aberrant regulation of innate and adaptive immunity genes in the pathogenesis of systemic lupus erythematosus. Nat Genet. 2015; 47(12):1457-1464. [PubMed: 26502338]

7. Cooper GS, Miller FW, Pandey JP. The role of genetic factors in autoimmune disease: implications for environmental research. Environ Health Perspect. 1999; 107(Suppl 5):693-700.

8. Ballestar E. Epigenetics lessons from twins: prospects for autoimmune disease. Clin Rev Allergy Immunol. 2010; 39(1):30-41. [PubMed: 19653134]

9. Parks CG, Cooper GS, Nylander-French LA, Sanderson WT, Dement JM, Cohen PL, et al. Occupational exposure to crystalline silica and risk of systemic lupus erythematosus: a populationbased, case-control study in the southeastern United States. Arthritis Rheum. 2002; 46(7):1840 1850. [PubMed: 12124868]

10. Parks CG, Cooper GS, Nylander-French LA, Storm JF, Archer JD. Assessing exposure to crystalline silica from farm work: a population-based study in the Southeastern United States. Ann Epi. 2003; 13(5):385-92.

11. Wang J, Pan HF, Ye DQ, Su H, Li XP. Moderate alcohol drinking might be protective for systemic lupus erythematosus: a systematic review and meta-analysis. Clinical Rheum. 2008; 27(12):155763.

12. Costenbader KH, Kim DJ, Peerzada J, Lockman S, Nobles-Knight D, Petri M, et al. Cigarette Smoking and the Risk of Systemic Lupus Erythematosus: A Meta-Analysis. Arthritis Rheum. 2004; 50:849-857. [PubMed: 15022327]

13. Sanchez-Guerrero J, Karlson EW, Liang MH, Hunter DJ, Speizer FE, Colditz GA. Past use of oral contraceptives and the risk of developing systemic lupus erythematosus. Arthritis Rheum. 1997; 40(5):804-808. [PubMed: 9153539]

14. Costenbader KH, Feskanich D, Stampfer MJ, Karlson EW. Reproductive and Menopausal Factors and Risk of Systemic Lupus Erythematosus in Women. Arthritis Rheum. 2007; 56(4):1251-1262. [PubMed: 17393454]

15. Parks CG, D'Aloisio AA, Sandler DP. Early Life Factors Associated with Adult- Onset Systemic Lupus Erythematosus in Women. Frontiers in immunology. 2016; 7:1-7. [PubMed: 26834743] 
16. Harris HR, Costenbader KH, Mu F, Kvaskoff M, Malspeis S, Karlson EW, et al. Endometriosis and the risks of systemic lupus erythematosus and rheumatoid arthritis in the Nurses' Health Study II. Annals of the rheumatic diseases. 2015; 0:1-6.

17. Parks CG, Cooper GS, Hudson LL, Dooley MA, Treadwell EL, St Clair EW, et al. Association of Epstein-Barr virus with systemic lupus erythematosus: Effect modification by race, age, and cytotoxic T lymphocyte-associated antigen 4 genotype. Arthritis Rheum. 2005; 52(4):1148-1159. [PubMed: 15818712]

18. Somers EC, Richardson BC. Environmental exposures, epigenetic changes and the risk of lupus. Lupus. 2014; 23(6):568-576. [PubMed: 24763540]

19. Javierre BM, Fernandez AF, Richter J, Al-Shahrour F, Martin-Subero JI, Rodriguez-Ubreva J, et al. Changes in the pattern of DNA methylation associated with twin discordance in systemic lupus erythematosus. Genome Res. 2010; 20(2):170-179. [PubMed: 20028698]

20. Oaks Z, Perl A. Metabolic control of the epigenome in systemic Lupus erythematosus. Autoimmunity. 2014; 47(4):256-64. [PubMed: 24128087]

21. Strickland FM, Li Y, Johnson K, Sun Z, Richardson BC. CD4(+) T cells epigenetically modified by oxidative stress cause lupus-like autoimmunity in mice. J Autoimmun. 2015; 62:75-80. [PubMed: 26165613]

22. Lightfoot YL, Blanco LP, Kaplan MJ. Metabolic abnormalities and oxidative stress in lupus. Curr Opin Rheumatol. 2017; 29(0):1-8. [PubMed: 27906751]

23. Moulton VR, Suarez-Fueyo A, Meidan E, Li H, Mizui M, Tsokos GC. Pathogenesis of Human Systemic Lupus Erythematosus: A Cellular Perspective. Trends Mol Med. 2017 Jul; 23(7):615635. [PubMed: 28623084]

24. Simard JF, Costenbader KH. What can epidemiology tell us about systemic lupus erythematosus? Int J Clin Pract. 2007; 61(7):1170-1180. [PubMed: 17577298]

25. Parks CG, Miller FW, Pollard KM, Selmi C, Germolec D, Joyce K, et al. Expert panel workshop consensus statement on the role of the environment in the development of autoimmune disease. Int J Mol Sci. 2014; 15(8):14269-97. [PubMed: 25196523]

26. Arbuckle MR, McClain MT, Rubertone MV, Scofield RH, Dennis GJ, James JA, et al. Development of autoantibodies before the clinical onset of systemic Lupus erythematosus. N Engl J Med. 2003; 349(16):1526-33. [PubMed: 14561795]

27. Satoh M, Chan EK, Ho LA, Rose KM, Parks CG, Cohn RD, et al. Prevalence and sociodemographic correlates of antinuclear antibodies in the United States. Arthritis \& Rheumatism. 2012; 64(7):2319-27. [PubMed: 22237992]

28. Arkema EV, Simard JF. Perinatal risk factors for future SLE: a population-based nested casecontrol study. Lupus. 2015; 24(8):869-74. [PubMed: 25672372]

29. Simard JF, Costenbader KH, Liang MH, Karlson EW, Mittleman MA. Exposure to maternal smoking and incident SLE in a prospective cohort study. Lupus. 2009; 18(5):431- 5. [PubMed: 19318396]

30. Miller FW, Alfredsson L, Costenbader KH, Kamen DL, Nelson LM, Norris JM, et al. Epidemiology of environmental exposures and human autoimmune diseases: findings from a National Institute of Environmental Health Sciences Expert Panel Workshop. Journal of autoimmunity. 2012; 39(4):259-271. [PubMed: 22739348]

31. Parks CG, Cooper GS. Occupational exposures and risk of systemic lupus erythematosus: a review of the evidence and exposure assessment methods in population- and clinic-based studies. Lupus. 2006; 15(11):728-736. [PubMed: 17153843]

32. Finckh A, Cooper GS, Chibnik LB, Costenbader KH, Watts J, Pankey H, et al. Occupational silica and solvent exposures and risk of systemic lupus erythematosus in urban women. Arthritis \& Rheumatology. 2006; 54(11):3648-3654.

33. Parks CG, Conrad K, Cooper GS. Occupational exposure to crystalline silica and autoimmune disease. Environ Health Perspect. 1999; 107(Suppl 5):793-802. [PubMed: 10970168]

34. Li X, Sundquist J, Sundquist K, Zoller B. Occupational risk factors for systemic lupus erythematosus: a nationwide study based on hospitalizations in Sweden. J Rheumatol. 2012; 39(4): 743-751. [PubMed: 22382347] 
35. Gold LS, Ward MH, Dosemeci M, De Roos AJ. Systemic autoimmune disease mortality and occupational exposures. Arthritis Rheum. 2007; 56(10):3189-3201. [PubMed: 17907164]

36. Blanc PD, Jarvholm B, Toren K. Prospective risk of rheumatologic disease associated with occupational exposure in a cohort of male construction workers. Am J Med. 2015; 128(10):10941101. [PubMed: 26007670]

37. Pollard KM. Silica, silicosis, and autoimmunity. Frontiers in immunology. 2016; 7:1-7. [PubMed: 26834743]

38. Brown JM, Archer AJ, Pfau JC, Holian A. Silica accelerated systemic autoimmune disease in lupus-prone New Zealand mixed mice. Clinical \& Experimental Immunology. 2003; 131(3):415421. [PubMed: 12605693]

39. Bates MA, Brandenberger C, Langohr I, Kumagai K, Harkema JR, Holian A, et al. Silica Triggers Inflammation and Ectopic Lymphoid Neogenesis in the Lungs in Parallel with Accelerated Onset of Systemic Autoimmunity and Glomerulonephritis in the Lupus- Prone NZBWF1 Mouse. PloS one. $2015 ; 10(5): 1-25$.

40. Olsson AR, Skogh T, Axelson O, Wingren G. Occupations and exposures in the work environment as determinants for rheumatoid arthritis. J Occup Env Med. 2004; 61(3):233-238.

41. Parks CG, De Roos AJ. Pesticides, chemical and industrial exposures in relation to systemic lupus erythematosus. Lupus. 2014; 23(6):527-536. [PubMed: 24763537]

42. Zolnik BS, Gonzalez-Fernandez A, Sadrieh N, Dobrovolskaia MA. Minireview: nanoparticles and the immune system. Endocrinology. 2010; 151(2):458-465. [PubMed: 20016026]

43. Webber MP, Moir W, Crowson CS, Cohen HW, Zeig-Owens R, Hall CB, et al. Post-September 11, 2001, Incidence of Systemic Autoimmune Diseases in World Trade Center-Exposed Firefighters and Emergency Medical Service Workers. Mayo Clin Proc. 2016; 91(1):23-32. [PubMed: 26682920]

44. Sunil VR, Vayas KN, Fang M, Zarbl H, Massa C, Gow AJ, et al. World Trade Center (WTC) dust exposure in mice is associated with inflammation, oxidative stress and epigenetic changes in the lung. Experimental and molecular pathology. 2017; 102(1):50-58. [PubMed: 27986442]

45. Kazeros A, Zhang E, Cheng X, Shao Y, Liu M, Qian M, et al. Systemic inflammation associated with world trade center dust exposures and airway abnormalities in the local community. Journal of occupational and environmental medicine. 2015; 57(6):610-616. [PubMed: 26053363]

46. Wu M, Gordon RE, Herbert R, Padilla M, Moline J, Mendelson D, et al. Case report: Lung disease in World Trade Center responders exposed to dust and smoke: carbon nanotubes found in the lungs of World Trade Center patients and dust samples. Environmental health perspectives. 2010; 118(4):499-504. [PubMed: 20368128]

47. Bernatsky S, Smargiassi A, Johnson M, Kaplan GG, Barnabe C, Svenson L, et al. Fine particulate air pollution, nitrogen dioxide, and systemic autoimmune rheumatic disease in Calgary, Alberta. Environ Res. 2015; 140:474-478. [PubMed: 25988990]

48. Bernatsky S, Smargiassi A, Barnabe C, Svenson LW, Brand A, Martin RV, et al. Fine particulate air pollution and systemic autoimmune rheumatic disease in two Canadian provinces. Environ Res. 2016; 146:85-91. [PubMed: 26724462]

49. Pryor WA, Stone K. Oxidants in cigarette smoke. Radicals, hydrogen peroxide, peroxynitrate, and peroxynitrite. Ann N Y Acad Sci. 1993; 686:12-27. [PubMed: 8512242]

50. Bijl M, Horst G, Limburg P, Kallenberg C. Effects of smoking on activation markers, Fas expression and apoptosis of peripheral blood lymphocytes. Eur J Clin Invest. 2001; 31:550-3. [PubMed: 11422406]

51. Arnson Y, Shoenfeld Y, Amital H. Effects of tobacco smoke on immunity, inflammation and autoimmunity. J Autoimmun. 2010; 34:J258-J65. [PubMed: 20042314]

52. Barbhaiya M, Tedeschi S, Lu B, Malspeis S, Sparks JA, Karlson EW, et al. Cigarette Smoking Increases the Risk of Anti-Double-Stranded DNA Positive SLE Among Women in the Nurses' Health Studies [abstract]. Arthritis Rheumatol. 2016; 68(Suppl 10):2988.

53. Parks CG, Cooper GS, Dooley MA, Park MM, Treadwell EL, Gilkeson GS. Childhood agricultural and adult occupational exposures to organic dusts in a population-based case-control study of systemic lupus erythematosus. Lupus. 2008; 17(8):711-719. [PubMed: 18625648] 
54. Cooper GS, Dooley MA, Treadwell EL, St Clair EW, Parks CG, Gilkeson GS. Hormonal, environmental, and infectious risk factors for developing systemic lupus erythematosus [review]. Arthritis Rheum. 1998; 41:1714-1724. [PubMed: 9778212]

55. Cooper GS, Wither J, Bernatsky S, Claudio JO, Clarke A, Rioux JD, et al. Occupational and environmental exposures and risk of systemic lupus erythematosus: silica, sunlight, solvents. Rheumatology. 2010; 49(11):2172-2180. [PubMed: 20675707]

56. Cooper GS, Parks CG, Treadwell EL, St Clair EW, Gilkeson GS, Dooley MA. Occupational risk factors for the development of systemic lupus erythematosus. J Rheumatol. 2004; 31(10):19281933. [PubMed: 15468355]

57. Kilburn KH, Warshaw RH. Prevalence of symptoms of systemic lupus erythematosus (SLE) and of fluorescent antinuclear antibodies associated with chronic exposure to trichloroethylene and other chemicals in well water. Env Res. 1992; 57(1):1- 9. [PubMed: 1740091]

58. Halperin W, Vogt R, Sweeney MH, Shopp G, Fingerhut M, Petersen M. Immunological markers among workers exposed to 2,3,7,8-tetrachlorodibenzo-p-dioxin. J Occup Env Med. 1998; 55(11): 742-749.

59. Parks CG, Walitt BT, Pettinger M, Chen JC, De Roos AJ, Hunt J, et al. Insecticide use and risk of rheumatoid arthritis and systemic lupus erythematosus in the Women's Health Initiative Observational Study. Arthritis Care Res. 2011; 63(2):184-194.

60. Chopra M, Schrenk D. Dioxin toxicity, aryl hydrocarbon receptor signaling, and apoptosispersistent pollutants affect programmed cell death. Crit Rev Toxicol. 2011; 41(4):292-320. [PubMed: 21323611]

61. Tsai PC, Ko YC, Huang W, Liu HS, Guo YL. Increased liver and lupus mortalities in 24-year follow-up of the Taiwanese people highly exposed to polychlorinated biphenyls and dibenzofurans. The Science of the total environment. 2007; 374:216-222. [PubMed: 17257654]

62. Sanchez-Guerrero J, Karlson EW, Colditz GA, Hunter DJ, Speizer FE, Liang MH. Hair dye use and the risk of developing systemic lupus erythematosus. Arthritis Rheum. 1996; 39(4):657-662. [PubMed: 8630117]

63. Gilbert KM, Rowley B, Gomez-Acevedo H, Blossom SJ. Coexposure to mercury increases immunotoxicity of trichloroethylene. Toxicological sciences : an official journal of the Society of Toxicology. 2011 Feb; 119(2):281-292. [PubMed: 21084432]

64. Lu-Fritts PY, Kottyan LC, James JA, Xie C, Buckholz JM, Pinney SM, et al. Association of Systemic Lupus Erythematosus with Uranium Exposure in a Community Living Near a UraniumProcessing Plant: A Nested Case-Control Study. Arthritis \& Rheumatology. 2014; 66(11):31053112. [PubMed: 25103365]

65. Gardner RM, Nyland JF, Silva IA, Ventura AM, de Souza JM, Silbergeld EK. Mercury exposure, serum antinuclear/antinucleolar antibodies, and serum cytokine levels in mining populations in Amazonian Brazil: a cross-sectional study. Environmental Research. 2010; 110(4):345-354. [PubMed: 20176347]

66. Dinse GE, Jusko TA, Whitt IZ, Co CA, Parks CG, Satoh M, et al. Associations Between Selected Xenobiotics and Antinuclear Antibodies in the National Health and Nutrition Examination Survey, 1999-2004. Environ Health Perspect. 2016; 124(4):426- 436. [PubMed: 26252071]

67. Zamansky GB. Sunlight-induced pathogenesis in systemic lupus erythematosus. J Invest Dermatol. 1985; 85:179-180. [PubMed: 4031534]

68. Runger TM, Epe B, Moller K. Processing of directly and indirectly ultraviolet-induced DNA damage in human cells. Recent Results Cancer Res. 1995; 139:31-42. [PubMed: 7597299]

69. Andrade F, Casciola-Rosen LA, Rosen A. Generation of novel covalent RNA-protein complexes in cells by ultraviolet B irradiation: implications for autoimmunity. Arthritis Rheum. 2005; 52(4): 1160-70. [PubMed: 15818701]

70. Yung R, Powers D, Johnson K, Amento E, Carr D, Laing T, et al. Mechanisms of drug-induced lupus. II. T cells overexpressing lymphocyte function-associated antigen 1 become autoreactive and cause a lupuslike disease in syngeneic mice. J Clin Invest. 1996; 97(12):2866-2871. [PubMed: 8675699]

71. Aubin F. Mechanisms involved in ultraviolet light-induced immunosuppression. Eur J Dermatol. 2003; 13:515-523. [PubMed: 14721768] 
72. Fraser PA, Ding W, Mohseni M, Treadwell EL, Dooley MA, St Clair EW, et al. Glutathione STransferase M Null Homozygosity and Risk of Systemic Lupus Erythematosus Associated with Sun Exposure: A Possible Gene-Environment. J Rheumatol. 2003; 30(2):276-282. [PubMed: 12563680]

73. Barbhaiya M, Costenbader KH. Ultraviolet radiation and systemic lupus erythematosus. Lupus. 2014; 23(6):588-595. [PubMed: 24763542]

74. Kuhn A, Beissert S. Photosensitivity in lupus erythematosus. Autoimmunity. 2005; 38(7):519-529. [PubMed: 16373257]

75. Cantorna MT, Mahon BD. Mounting Evidence for Vitamin D as an Environmental Factor Affecting Autoimmune Disease Prevalence. Exp Biol Med. 2004; 229:1136-1142.

76. Costenbader KH, Feskanich D, Benito-Garcia E, Holmes M, Karlson E. Vitamin D intake and risks of systemic lupus erythematosus and rheumatoid arthritis in women. Ann Rheum Dis. 2008; 67(4): 530-535. [PubMed: 17666449]

77. Costenbader KH, Kang JH, Karlson EW. Antioxidant intake and risks of rheumatoid arthritis and systemic lupus erythematosus in women. Am J Epi. 2010; 172(2):205-216.

78. Young KA, Munroe ME, Guthridge JM, Kamen DL, Niewold TB, Gilkeson GS, et al. Combined role of vitamin D status and CYP24A1 in the transition to systemic lupus erythematosus. Ann Rheum Dis. 2016; 0:1-6.

79. Montanaro A, Bardana EJ Jr. Dietary amino acid-induced systemic lupus erythematosus. Rheum Dis Clin North Am. 1991; 17(2):323-332. [PubMed: 1862241]

80. Bengtsson AA, Rylander L, Hagmar L, Nived O, Sturfelt G. Risk factors for developing systemic lupus erythematosus: a case-control study in southern Sweden. Rheumatology. 2002; 41(5):563571. [PubMed: 12011382]

81. Costenbader KH, Kang JH, Karlson EW. Antioxidant intake and risks of rheumatoid arthritis and systemic lupus erythematosus in women. Am J Epidemiol. 2010; 172(2):205-216. [PubMed: 20534819]

82. Pan Y, Ke H, Yan Z, Geng Y, Asner N, Palani S, et al. The western-type diet induces anti-HMGB1 autoimmunity in Apoe-/- mice. Atherosclerosis. 2016; 251:31-38. [PubMed: 27240253]

83. Strickland FM, Hewagama A, Wu A, Sawalha AH, Delaney C, Hoeltzel MF, et al. Diet influences expression of autoimmune-associated genes and disease severity by epigenetic mechanisms in a transgenic mouse model of lupus. Arthritis Rheum. 2013; 65(7):1872-1881. [PubMed: 23576011]

84. Waldschmidt TJ, Cook RT, Kovacs EJ. Alcohol and inflammation and immune responses: summary of the 2006 Alcohol and Immunology Research Interest Group (AIRIG) meeting. Alcohol. 2008; 42(2):137-142. [PubMed: 18358993]

85. Wirleitner B, Schroecksnadel K, Winkler C, Schennach H, Fuchs D. Resveratrol suppresses interferon-gamma-induced biochemical pathways in human peripheral blood mononuclear cells in vitro. Immunol Lett. 2005; 100(2):159-63. [PubMed: 16154495]

86. Sun NJ, Woo SH, Cassady JM, Snapka RM. DNA polymerase and topoisomerase II inhibitors from Psoralea corylifolia. J Nat Prod. 1998; 61:362-366. [PubMed: 9544566]

87. Gonzalez-Quintela A, Alende R, Gude F, Campos J, Rey J, Meijide LM, et al. Serum levels of immunoglobulins (IgG, $\operatorname{IgA}, \operatorname{IgM})$ in a general adult population and their relationship with alcohol consumption, smoking and common metabolic abnormalities. Clin Exp Immunol. 2008; 151(1): 42-50. [PubMed: 18005364]

88. Barbhaiya M, Lu B, Sparks JA, Malspeis S, Chang SC, Karlson EW, et al. Influence of Alcohol Consumption on the Risk of Systemic Lupus Erythematosus among Women in the Nurses' Health Study Cohorts. Arthritis Care Res. 2017; 69(3):384-392.

89. Cooper GS, Dooley MA, Treadwell EL, St Clair EW, Gilkeson GS. Risk factors for development of systemic lupus erythematosus: allergies, infections, and family history. J Clin Epidemiol. 2002; 55(10):982-989. [PubMed: 12464374]

90. Grimaldi-Bensouda L, Le Guern V, Kone-Paut I, Aubrun E, Fain O, Ruel M, et al. The risk of systemic lupus erythematosus associated with vaccines: an international case-control study. Arthritis Rheum. 2014; 66(6):1559-1567. 
91. James JA, Kaufman KM, Farris AD, Taylor-Albert E, Lehman TJ, Harley JB. An increased prevalence of Epstein-Barr virus infection in young patients suggests a possible etiology for systemic lupus erythematosus. J Clin Invest. 1997; 100(12):3019-3026. [PubMed: 9399948]

92. Ulff-Moller CJ, Nielsen NM, Rostgaard K, Hjalgrim H, Frisch M. Epstein-Barr virus-associated infectious mononucleosis and risk of systemic lupus erythematosus. Rheumatology. 2010; 49:1706-1712. [PubMed: 20488925]

93. Hanlon P, Avenell A, Aucott L, Vickers MA. Systematic review and meta-analysis of the seroepidemiological association between Epstein-Barr virus and systemic lupus erythematosus. Arthritis Res Ther. 2014; 16(R3):1-11.

94. Nielsen PR, Kragstrup TW, Deleuran BW, Benros ME. Infections as risk factor for autoimmune diseases-A nationwide study. Journal of autoimmunity. 2016; 74:176. [PubMed: 27267460]

95. Grimaldi CM, Cleary J, Dagtas AS, Moussai D, Diamond B. Estrogen alters thresholds for B cell apoptosis and activation. J Clin Invest. 2002; 109(12):1625-1633. [PubMed: 12070310]

96. Lahita RG, Kunkel HG, Bradlow HL. Increased oxidation of testosterone in systemic lupus erythematosus. Arthritis Rheum. 1983; 26(12):1517-1521. [PubMed: 6651898]

97. Lateef A, Petri M. Hormone replacement and contraceptive therapy in autoimmune diseases. Journal of autoimmunity. 2012; 38(2):J170-176. [PubMed: 22261500]

98. Bernier MO, Mikaeloff Y, Hudson M, Suissa S. Combined oral contraceptive use and the risk of systemic lupus erythematosus. Arthritis Rheum. 2009; 61:476-481. [PubMed: 19333988]

99. Petri M, Thompson E, Abusuwwa R, Huang J, Garrett E. BALES: The Baltimore Lupus Environmental Study [abstract]. Arthritis Rheum. 2001; 44(Suppl 9):S331.

100. Kiyohara C, Washio M, Horiuchi T, Tada Y, Asami T, Ide S, Takahashi H, Kobashi G. Kyushu Sapporo SLE (KYSS) Study Group. Cigarette smoking, N-acetyltransferase 2 polymorphisms and systemic lupus erythematosus in a Japanese population. Lupus. 2009; 18(7):630-8. [PubMed: 19433464]

101. Kiyohara C, Washio M, Horiuchi T, Tada Y, Asami T, Ide S, Atsumi T, Kobashi G, Takahashi H. Kyushu Sapporo SLE (KYSS) Study Group. Cigarette smoking, STAT4 and TNFRSF1B polymorphisms, and systemic lupus erythematosus in a Japanese population. J Rheumatol. 2009; 36(10):2195-203. [PubMed: 19684152]

102. Kiyohara C, Washio M, Horiuchi T, Asami T, Ide S, Atsumi T, Kobashi G, Takahashi H, Tada Y. Kyushu Sapporo SLE (KYSS) Study Group. Risk modification by CYP1A1 and GSTM1 polymorphisms in the association of cigarette smoking and systemic lupus erythematosus in a Japanese population. Scand J Rheumatol. 2012; 41(2):103-9. [PubMed: 22217397]

103. Kiyohara C, Washio M, Horiuchi T, Asami T, Ide S, Atsumi T, Kobashi G, Takahashi H, Tada Y. Kyushu Sapporo SLE (KYSS) Study Group. Modifying effect of N-acetyltransferase 2 genotype on the association between systemic lupus erythematosus and consumption of alcohol and caffeine-rich beverages. Arthritis Care Res. 2014; 66(7):1048-56. 


\section{Research agenda}

- $\quad$ Specific evidence for potential causal associations with SLE onset is strongest for silica dust exposure, current cigarette smoking, exogenous estrogens (in oral contraceptives and postmenopausal hormones), and protective effects of low to moderate alcohol consumption.

- Additional factors potentially increasing risk of SLE, but requiring confirmation, include other respiratory exposures, such as other silicates and air pollution, as well as pesticides, environmental estrogens, and solvents.

- Various environmental exposures may act in different ways, some decreasing the threshold for the development of autoimmune disease in general (e.g. crystalline silica associated with several autoimmune connective tissue diseases) and others precipitating the onset of clinical manifestations in individuals with brewing subclinical disease (e.g. ultraviolet light).

- In addition to the challenges of exposure assessment, the study of environmental factors is complicated by the potential for exposures to act throughout the life course, with some time windows in life representing more vulnerable windows for the development of SLE than others.

- $\quad$ Studies identifying the role of modifiable environmental risk factors in the development of SLE will advance our understanding of disease pathogenesis and could lead to strategies to prevent disease.

- $\quad$ Research will be advanced through studies in susceptible subgroups and should consider exposures across the life course. 


\section{Environmental influences on the development of SLE across the life-course}

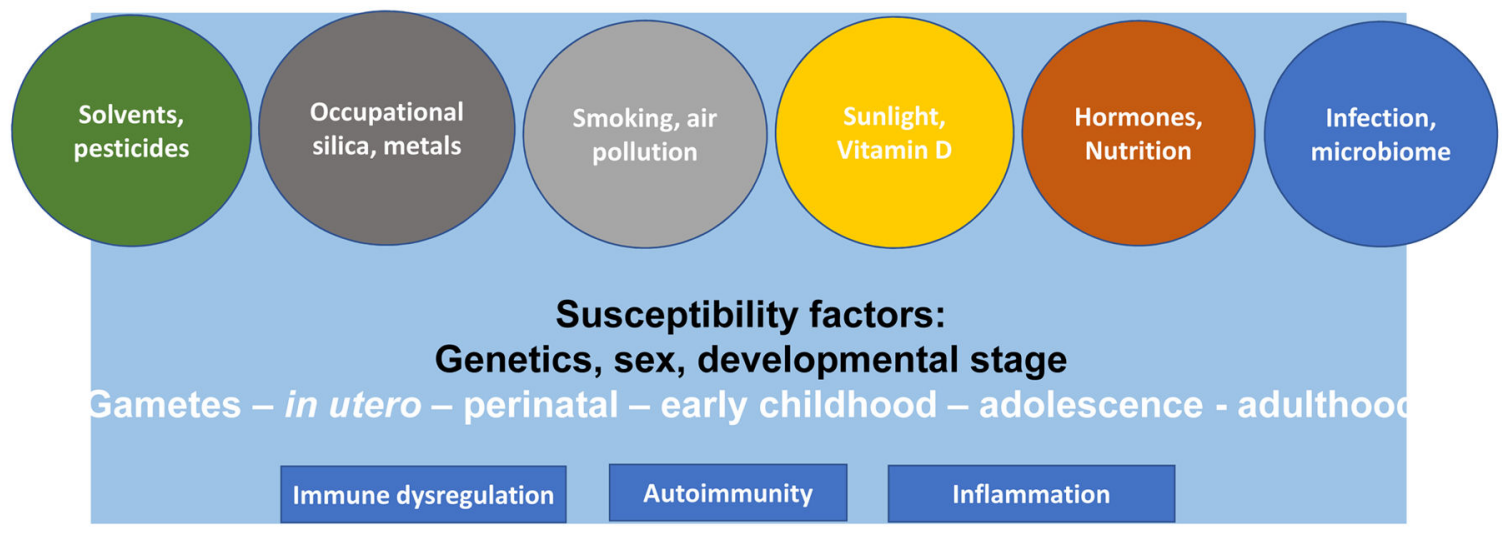

\section{SLE, clinical features}

Figure 1.

Environmental Influences on SLE across the lifecourse. ${ }^{1}$

${ }^{1}$ Against a background of genetic susceptibility, sex (female), and developmental stage, multiple environmental exposures and stochastic factors contribute together and over time to epigenetic changes and immune dysregulation through a variety of mechanisms, resulting in functional changes, loss of tolerance and autoimmunity, plus inflammation, and leading to the development of SLE. 


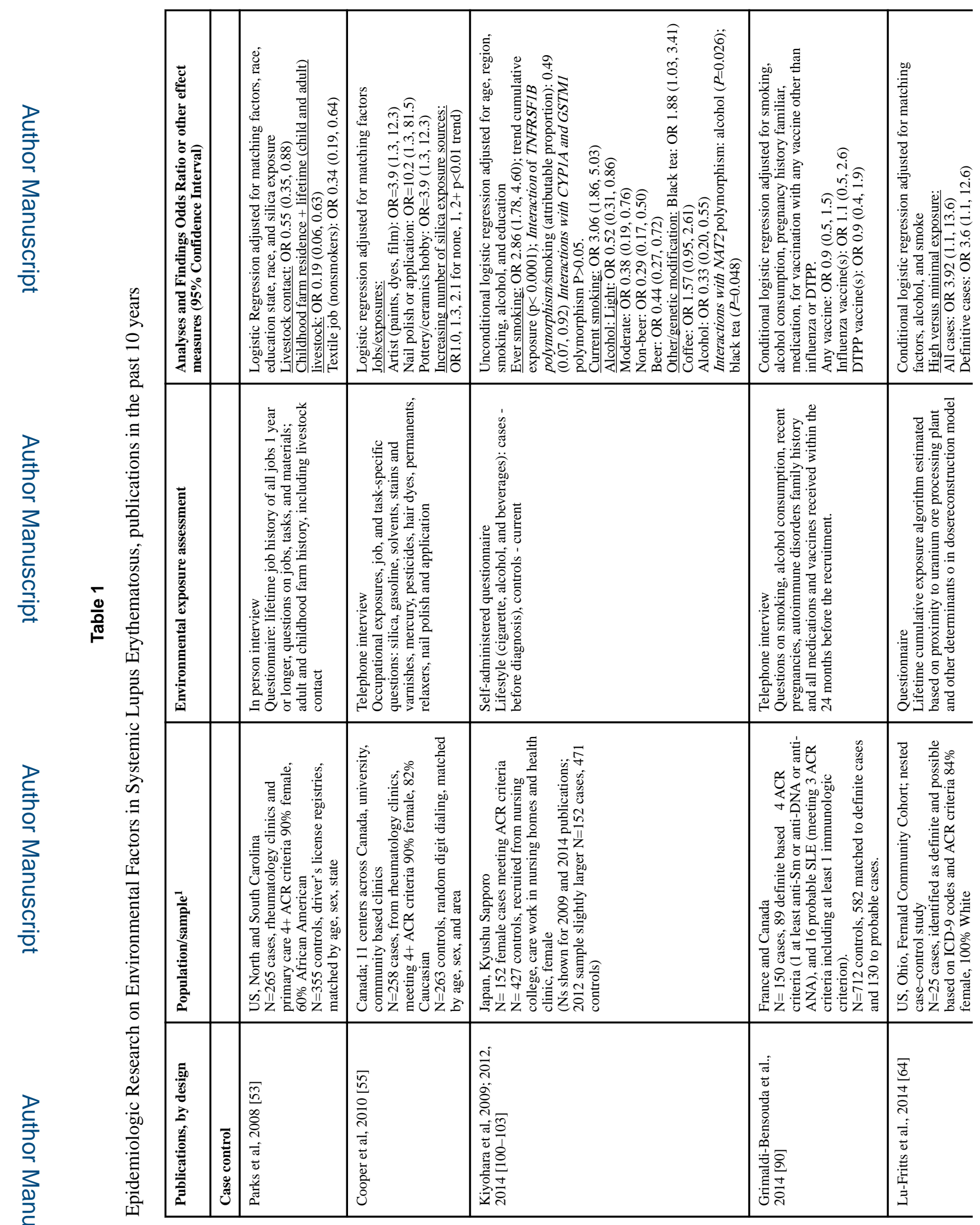

Best Pract Res Clin Rheumatol. Author manuscript; available in PMC 2018 October 21. 


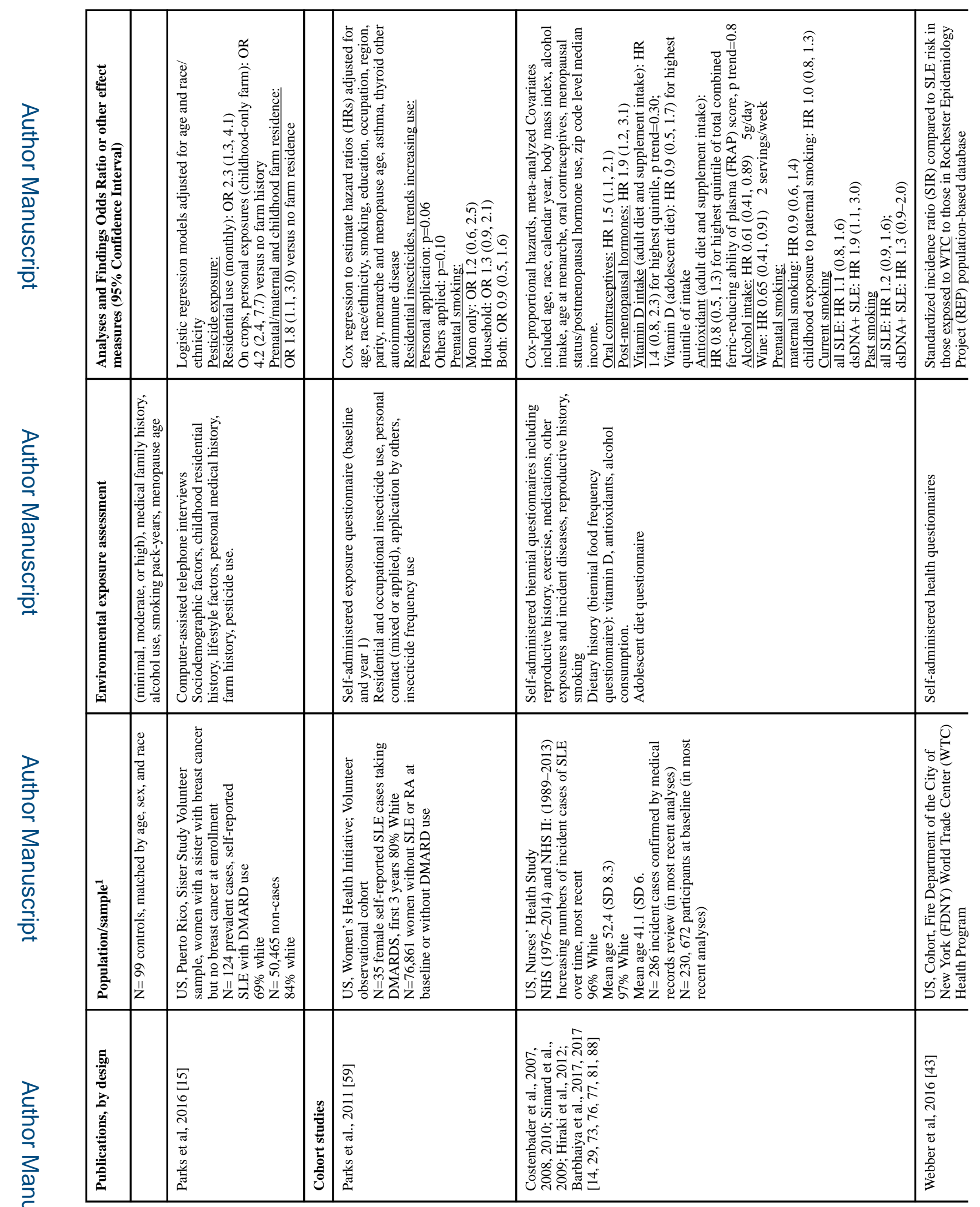

Best Pract Res Clin Rheumatol. Author manuscript; available in PMC 2018 October 21. 


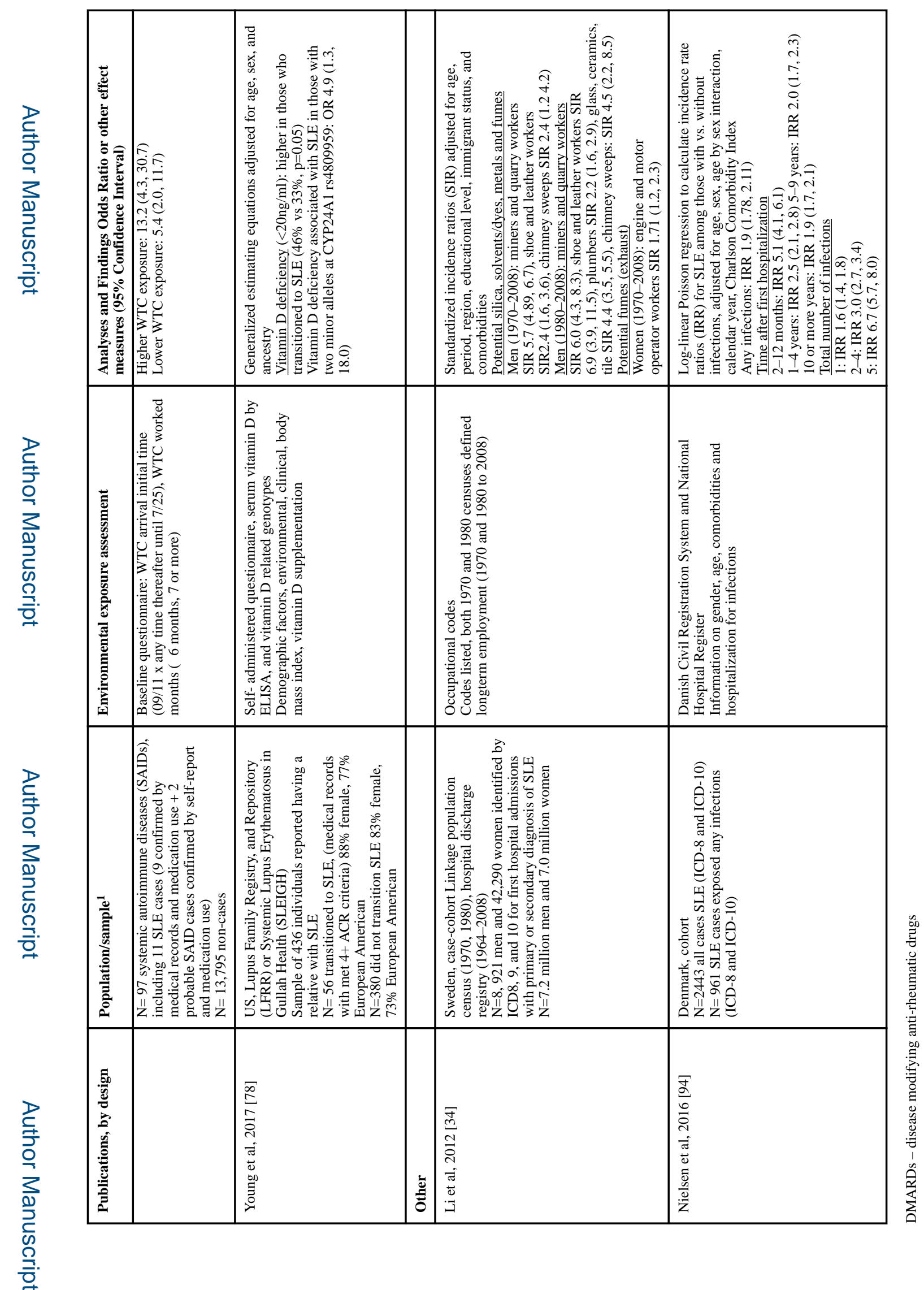

Best Pract Res Clin Rheumatol. Author manuscript; available in PMC 2018 October 21. 